\title{
Cars, trees, and house prices: Evaluation of the residential environment as a function of numbers of cars and trees in the street
}

\author{
Henk Staats $^{\mathrm{a}, *}$, Ritwik Swain ${ }^{\mathrm{b}}$ \\ ${ }^{a}$ Department of Social, Economic, and Organizational Psychology, Leiden University, the Netherlands \\ ${ }^{\mathrm{b}}$ Centre for Accident Research and Road Safety (CARRS - Q), University of Queensland, Australia
}

\section{A R T I C L E I N F O}

Handling Editor: Wendy Chen

Keywords:

cars

trees

house price

affect

neighborhood

environmental psychology

\begin{abstract}
A B S T R A C T
When imagining a perfect home, many people visualize a tree-lined, leafy neighborhood, and a road that only has a few parked cars. But how strongly do people really appreciate having fewer parked cars and more street trees, both in terms of an affective appreciation of the home, and in terms of a price estimate of the home? This experiment, with 281 participants recruited from Leiden University, aimed to answer this question by using four photographs of street scenes with different architectural styles and digitally modifying them to manipulate the number of parked cars (4 levels; from no cars to overfull) and street trees ( 3 levels; from no trees to $50 \%$ density). The four photographs were presented to participants on a computer screen in random order, with a random level of the cars and trees variables in the street in each photograph. Participants were asked to rate the neighborhood in terms of safety, friendliness and beauty, and to rate two residences in each of the four photographs presented in terms of attractiveness, estimated sale price and estimated income of the current owner. Analyses using multilevel modelling found that both the neighborhoods and the residences were appreciated less when the street was overfull with parked cars. Participants estimated approximately $5 \%$ higher prices for residences when there were trees in the street, as well as rating the neighborhood as more attractive. The data were consistent with the hypothesis that neighborhood appraisal mediates the relationship between cars and affective appreciation of the residence as well as the hypothesis that neighborhood appraisal mediates the relationship between trees and price estimation.
\end{abstract}

\section{Introduction}

When looking for a new home, prospective buyers will also take into consideration the house's location with respect to the properties of the immediate and extended neighborhood, like the intensity of traffic in the streets, the availability of shops and services, as well as the presence of parks and green spaces nearby (Bonaiuto and Alves, 2012).

Luttik (2000) argues that if certain environmental factors' effects on house prices can be quantified, then it can be used as stronger justification in policy-making processes, for example to ensure that vulnerable amenities, like open space and presence of green, are given sufficient attention and protection. In this vein, this study investigates the influence of two environmental features in particular: the number of parked cars and the number of street trees. We investigate how these two environmental elements in combination influence the affective evaluation of houses, as well as their estimated sale price, and look at neighborhood appraisal, in particular the experience of pleasantness of the street where the house is located, as a potential mediator. Our general expectation is that the presence of cars may detract from the aesthetic and social quality of a street, and that the presence of trees may compensate for this loss and increase street quality. Street quality will consecutively influence the affective and economic value of houses in that street.

\subsection{Cars}

The number of parked cars in a street influences how the neighborhood is perceived. Isaacs's (2000) study on the aesthetic experience of urban pedestrian places gives strong evidence that pedestrians prefer streets with less traffic and fewer parked cars. Mullan (2003) studied the perceptions of adolescents in Cardiff, UK, who reported that the street in front of their home was always full of parked cars, and found that this made the street child-unfriendly, experienced as unsafe after dark, and in general less amenable to socializing among neighbors. This is in line with other studies such as that of Jurkovič's (2014) where urban residents reported that parked cars impeded their usage of open

\footnotetext{
* Corresponding author at: PO Box 9555, 2300 RB, Leiden, the Netherlands.

E-mail address: Staats@fsw.leidenuniv.nl (H. Staats).
} 
public places, and Hunter and Baumers (1982) finding that urban residents who do not feel socially integrated to the neighborhood fear crime more when there is more street traffic. It is also in line with Jacobsen et al.'s (2000) finding that a high number of parked cars can be dangerous for children because car drivers will be less likely to see children between parked cars.

Having too many parked cars on the road is not only unappealing in terms of safety and aesthetics but it is also unappealing for car users who need to find a regular place to park their car. Shoup (1994) refers to traffic engineers who commonly prescribe the optimal ratio between parked cars and vacant parking spaces as 6:1 (i.e. that of seven spaces, six should be filled). This ensures that car parking space wastage is minimized as well as ensuring that drivers can find spaces efficiently, and not waste time by "cruising" and causing congestion. However, homebuyers will probably have less interest in minimizing the number of unused parking spots because they will welcome the extra space on the street. A recent study (Guo, 2013) shows that the availability of onstreet parking increases car ownership, suggestive of the attractiveness of parking space. Therefore, it is more reasonable to presume that residents would prefer rather few parked cars on the street. On the other hand one might speculate that a street without any parked cars is not desirable for homebuyers either. A complete absence of cars might be perceived as a sign that the street's residents cannot afford to own cars, or that the neighborhood is deserted, and therefore unsafe because of a lack of "eyes on the street" (Jacobs, 1961). However, previous literature has not closely examined this, and so this study has an opportunity to discover something new, if a non-linear relationship is found between the number of parked cars and appreciation of a house.

\subsection{Urban vegetation's benefits to the urban environment}

A wide variety of literature (e.g., Mullaney et al., 2015; Roy et al., 2012; Smardon, 1988; Van den Berg et al., 2007) provides a plethora of reasons as to why an urban environment with sufficient vegetation, street trees in particular, is beneficial to and preferred by that environment's residents. These benefits can be divided into three subsets: the physical, the psychological and the economic.

Urban trees have the ability to stabilize the surrounding microclimate by providing shade, wind reduction and glare reduction (Smardon, 1988). Trees are generally considered to narrow the temperature range in the air and increase humidity, leading to substantial savings in energy for heating and cooling (McPherson, 1994; Oke et al., 1989).

Furthermore, trees are known to improve the air quality by absorbing carbon dioxide (Kiran and Kinnary, 2011), and particulate matter (Maher et al., 2013).

People visually enjoy natural vegetation in a number of ways, such as observing the change of vegetation over the seasons, and the way our senses - such as smell, sound, memory - are pleasantly affected by urban greenery (Smardon, 1988) - possibly due to 'biophilia', the innate tendency to focus on life and lifelike processes (Grinde and Patil, 2009; Wilson, 1984). Ulrich et al. (1991) found that stressed individuals who encounter a non-threatening natural environment will experience reduced stress and feel restored by that nature. Staats et al. (2016) found that participants considered visiting a park the most restorative activity, in comparison to other urban leisure activities such as sitting in a café, walking in a shopping mall, or walking in a busy street. This, alongside Taylor et al.'s (2015) finding that increased density of urban street trees was associated with lower prescription rates of anti-depressants in London, highlights how urban greenery influences mental health. Hur et al. (2010) found that a neighborhood's 'vegetation rate' was indirectly related to overall neighborhood satisfaction. Hartig and Kahn (2016) point out that when architects gain better understanding of the psychological benefits of the natural experience, they can design urban environments to incorporate more greenery in their plans, leading to improved mental health among future residents. We therefore expect that vegetation rate will influence the evaluation of a house through its effect on the neighborhood.

Clearly, there is a wide range of benefits that urban vegetation brings to individuals and society. But the question remains, can these benefits be accounted for financially? Smardon (1988) states that there is evidence to suggest that "appraisers and property owners pay more for certain property with trees and adjacent to urban parks and open space areas" (p. 86). This premium was found to be as high as $12 \%$ for developed residential lots (Payne, 1973; Payne and Strom, 1975; Morales et al., 1976). Pandit et al. (2013) found that in Perth, street trees in front of a house could increase property value by a median of AU $\$ 16,889$; where the median house price was AU\$395,000 equivalent to approximately $4 \%$. Donovan and Butry (2010) found that in Portland, street trees added on average " $\$ 8870$ to the price of a house, which represents $3.0 \%$ of median sales price" (p. 81). Anderson and Cordell (1988) found that in Athens, Georgia, USA, single-family residences with an average of five trees in their front gardens were associated with a 3.5-4.5\% increase in sales price, in comparison to houses without trees. Anderson and Cordell (1988) compare their findings to the $7 \%$ increase found by Payne (1973) and the $6 \%$ increase found by Morales (1976) and ultimately conclude: "An estimate of $5 \%$ as the average value that trees may add to a single-family residence is in line with research using both direct and statistical strategies for controlling comparability" (p. 163). Interestingly, Saphores and Li (2012) qualify these findings as they find that trees on private property hardly affect house prices, but that trees on public ground or on other people's plots nearby do increase house price. "Although owners of single family detached properties in Los Angeles may like more trees, they do not seem to be willing to bear their costs." (Saphores and Li, 2012, p.386). A similar effect - increase in house price in streets with trees on public space, but decrease when trees are on private property - is reported by Pandit et al. (2014). We conclude that, regardless of what the exact percentage increase is, the evidence is clear in suggesting that street trees, at least those on public space, make adjacent properties financially more valuable. Worth noting is that all the studies cited report results based on a method of hedonic pricing, in which actual house prices are related to a large number of properties of the houses, and the effect of the variable of interest - presence of street trees - is singled out through statistically controlling for all other variables that are considered potentially relevant. An important advantage of the method is the external validity of the data, based on prices and properties of real houses, a drawback is the possibility that even despite a large number of statistical controls, unmeasured variables may influence the outcomes as it is impossible to actually measure all other variables (see e.g., Shimizu, 2014). An experimental approach in which only the variables of interest are manipulated prevents the existence of such confounds, sacrificing some external validity in favor of experimental control. We chose the experimental approach for our study.

\subsection{Goal of the study and hypotheses}

This study investigates whether a relationship exists between the combined presence of parked cars and street tree density on property value, expressed as price estimates and other evaluative measures, hereafter named House Evaluation, and whether these relationships are mediated by impressions of the neighborhood that may affect liking and preference, hereafter named Neighborhood Appraisal.

The hypotheses drawn from or inspired by the reviewed literature are the following:

1 The Number of Parked Cars in the Street is negatively related to House Evaluation.

2 Street Tree Density is positively related to House Evaluation.

3 Neighborhood Appraisal is positively related to House Evaluation.

4 The Number of Parked Cars is negatively related to Neighborhood 


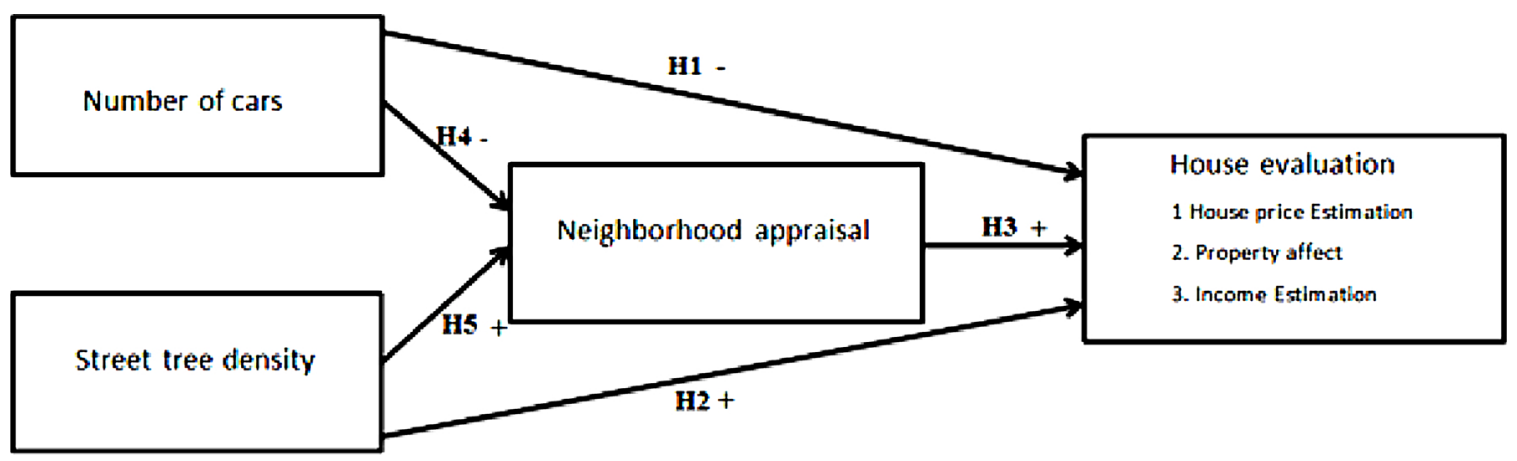

Fig. 1. The research model including Hypotheses 1-5. The plus ('+') and minus ('-') signs signify whether the relationship is hypothesised to be positive or negative respectively.

Appraisal.

5 Street Tree Density is positively related to Neighborhood Appraisal.

6 Neighborhood Appraisal is a mediator of the effect of Cars and Trees on House Evaluation.

Fig. 1 models the combined set of hypotheses.

\section{Method}

\subsection{Participants and design}

We recruited 281 participants with a mean age of 21.46 years (standard deviation $=4.36$ ), $74 \%$ of whom were female, from Leiden University via social media and advertising in the faculty building.

This study had a 4 (proportion of the curb occupied by parked cars) x 3 (street tree density) design. To make the data collected more valuable for future research, and our findings potentially more generalizable, an additional factor called 'Architectural Style' with four levels was included in the experiment.

Photographs were taken from four streets without cars and trees, in Leiden and The Hague, both cities in the west of the Netherlands. Each photograph was then edited using Adobe Photoshop CC2017. Pictures of cars and trees were artificially added to the photographs so as to manufacture differing levels of number of parked cars and street tree density. Each original photograph then had 12 edited versions, each representing every permutation of the $4 \times 3$ design. Ultimately, there were 48 different images of street scenes used ( 4 architectural styles x 4 levels of parked cars x 3 levels of street tree density).

\subsection{Materials}

Lab rooms with computers were used for the experiments so as to control as many external variables as possible. A digital camera was used to take the photographs which were then edited using Adobe Photoshop CC2017. Qualtrics (2019) was used for the web-based survey.

\subsection{Manipulations}

\subsubsection{Number of parked cars in the street ('Cars')}

The photographs were digitally modified to have four levels of parked cars. The first level, $0 \%$ represents zero cars parked on the street; $50 \%$ means that roughly half of the available street parking spaces were occupied; $100 \%$ represents all available parking spaces on the street occupied; $120 \%$ represents a street scene that is overflowing with parked cars - for example, cars parked in front gardens, on corners, and double-parked cars. Fig. 2 gives an example of how one photograph edited with varying levels of Cars looked.

\subsubsection{Street tree density ('Trees')}

In Maco and McPherson (2002), street tree density was measured by the percentage area of the street (including sidewalk covered by the canopy). Maco and McPherson (2002) refer to targets set by American Forests at the time as "25\% in urban residential and light commercial areas, and $50 \%$ in suburban residential areas" (p. 270) and so three levels were chosen for this experiment at $0 \%, 25 \%$, and $50 \%$ which approximately represent low, medium and high street tree density respectively. Measuring the exact area cover was not possible as twodimensional trees were digitally added to the photographs. The photographs in Fig. 3 depict all three levels of Trees.

\subsubsection{Architectural style ('architecture')}

Each of the four original photographs was from a different architectural style or period: 19th century, 1930's, 1960's, and high-rise. This was done to make the data more generalizable and was not used in any hypothesis or analysis. Between the four original photographs there are differences not only related to the architectural style, but also to features as the weather, size of the properties, or photographic lighting. All these features, not only architectural style, are stable features of each of the 12 permutated versions of the four original photographs. Thus controlled for, they are unlikely to affect the comparisons between the 12 versions of each photograph. Effects on the dependent variables will only be the result of the different levels of cars and trees in the street. Because of this comprehensive character of setting variables, not exclusively architectural style, the variable Architecture was included

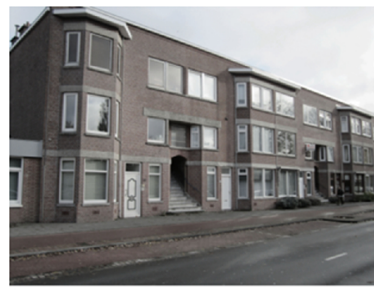

p\% Cars

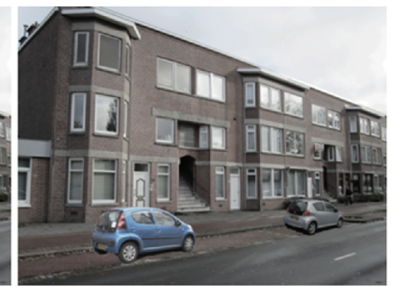

$50 \%$ Cars

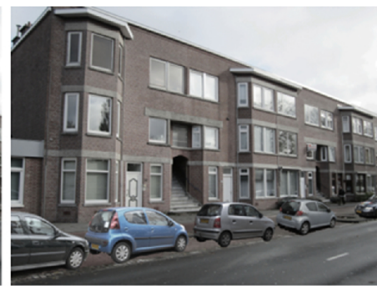

$100 \%$ Cars

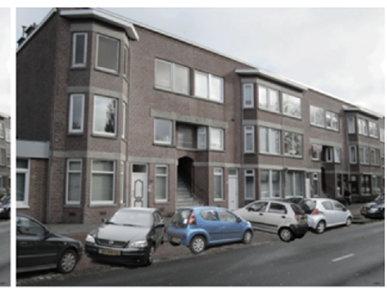

$120 \%$ Cars

Fig. 2. An example of the photograph of the 1960's architectural style with all four levels of the number of parked cars. 


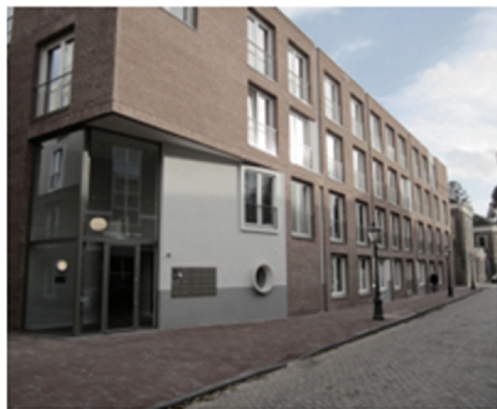

$0 \%$ Tree Cover

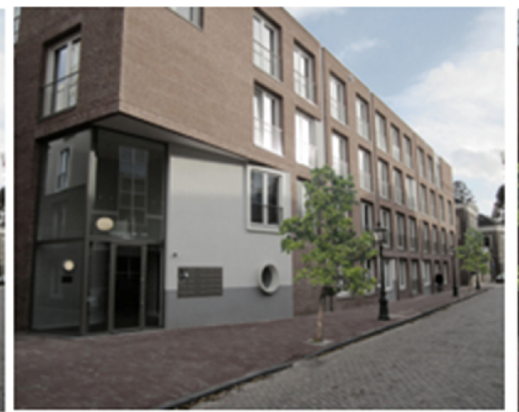

$25 \%$ Tree Cover

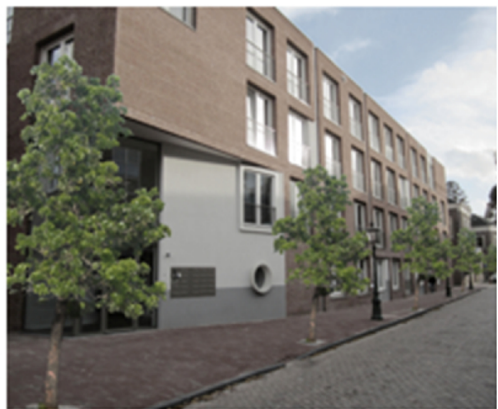

$50 \%$ Tree Cover

Fig. 3. An example of the 'high-rise' photograph with all three levels of street tree density.

in the analyses for correctional purposes only, and not to gain insight in differential effects of building style. We return to this issue in the Discussion.

\subsection{Measures}

\subsubsection{House evaluation}

Two properties, simply called Property A and Property B, were used as the objects to be evaluated in each street scene. Rating two instead of one property was expected to create higher reliability in the data on the House Evaluation variables per street scene. Similar to the reason underlying the strategy to use multiple items to measure a psychological construct, rating two properties instead of one could remove some of the error variance related to judgments of property in each particular combination of parked cars, tree density, and architectural style. Averaged ratings of the two properties in each photograph were used as the unit of analysis of House Evaluation. Thus constructing the House Evaluation measure reflects our interest in relative price levels. i.e., the price differences due to the various levels of the two independent variables, and not the absolute price per property.

Three measures were used for the House Evaluation construct per property. The first measure was 'House Price Estimation', a simple question asking: "What do you think the price of this property is?", followed by a slider with a minimum limit of $€ 25,000$ and a maximum limit of $€ 500,000$. House Price Estimation scores were the average of the scores of the two Properties A and B.

The second measure was a subscale called 'Property Affect', consisting of three five-point Likert scale items with answer options from 1 $=$ 'Strongly Disagree' to $5=$ 'Strongly Agree'. As these questions were asked twice per photograph - once for Property A and once for Property $\mathrm{B}$, the final subscale consisted of six variables, as each item appeared twice. Like in Orland et al.'s (1992) study, the first item was "I find this property attractive". The additional two items on the scale were "I would like to live in this property" and "I would purchase this house, if I could afford it". The Property Affect subscale was calculated as the average of the scores on these six items, where a score of 1 pertains to the worst possible appraisal and a score of 5 pertains to the best possible appraisal of the two properties combined. This Property Affect subscale was found to be highly reliable $(\alpha=.93)$.

The third measure, Income Estimation, derived from Hareli et al. (2016), asked participants: "What do you think the annual gross household income (i.e. total earning per year before any tax deduction) is of the people living in this property?" We chose this additional measure based on Hareli et al.'s reasoning that income is useful as an indirect measure of the perceived value of a house. To answer a slider was provided which had a minimum limit of $€ 15,000$ and a maximum of $€ 200,000$. Again, scores were averaged over the two properties A and B.

\subsubsection{Neighborhood appraisal}

This subscale was formed of three items that are generally considered major determinants of experienced neighborhood quality, in particular the area close to the home (see e.g., Bonaiuto and Alves, 2012) "This neighborhood appears to be safe", "This neighborhood appears to be friendly", and "This neighborhood appears to be beautiful". Participants responded to each item on a five point Likert scale with 1 being "Strongly disagree" and 5 being "Strongly agree". The Neighborhood Appraisal subscale was the average of these three items, where a score of 1 pertains to the worst possible appraisal of the neighborhood and a score of 5 pertains to the best possible appraisal of the neighborhood. This subscale was found to be highly reliable $(\alpha=.85)$.

\subsubsection{Photographs}

Three questions were asked at the end of the survey on whether participants were able to imagine themselves in the street scene, whether they found the photographs to be realistic, and whether they noticed anything unusual about the photographs.

\subsection{Procedure}

The experiment took place in Leiden University lab rooms. The first page of the online survey asked participants to select a box that indicated that they had read the information about the informed consent and agreed to the terms. The survey proper started with a few demographic questions. Then participants were shown four photographs, each architectural style once, in line with Orland et al.'s (1992) advice that it is important that subjects do not see more than one version of the same original, as the goal of the study and hypotheses then might become too obvious. Participants were instructed to imagine that they were looking to buy a house to live in and were currently walking in the street scenes; they should answer these questions as though they were a prospective buyer looking for a property to live in for themselves. Each of the four photographs that a participant saw was from a random level of the Number of Parked Cars variable and from a random level of the Street Tree Density. Underneath each photograph questions regarding Neighborhood Appraisal were asked. When these were completed an arrow appeared, pointing at the first property, Property A. In order to help participants to better imagine the property, some information was given describing the property in terms of size, number of bedrooms, bathrooms, whether the kitchen was separate from the living room, and presence of a garden or balcony. Then the questions on House Evaluation were asked. Next, on a new page, a different arrow appeared that pointed at a second property in the same photograph, Property B. Again some additional qualitative information on this property was displayed, and the questions on House Evaluation were asked in relation to Property B. This succession of descriptions and House Evaluation questions for the two properties was used for each of the four photographs. 
After participants had answered the questions for all four street scenes, they were debriefed and given either credits (obligatory to obtain for first-year students) or cash for their participation. Average response time for the survey was $13 \mathrm{~min}$ and $15 \mathrm{~s}$.

\subsubsection{Statistical analysis}

Qualtrics (2019), the online survey tool used for this experiment, produced a data file which was then analyzed using SPSS Version 24.

\subsubsection{Multi-level modelling (MLM)}

Because the assumption of independent observations is violated, as each participant rated more than one photograph, a regular ANOVA analysis would not be appropriate. Using MLM would account for the variance caused by each participant, as each picture is a variable that is nested within each participant, through the use of a random intercept for each subject.

\subsubsection{Mediation analyses}

Hypothesis 6 states that Neighborhood Appraisal mediates the effect of Cars and Trees on House Evaluation (see also Fig. 1). Since testing for mediation effects in an MLM context can be complicated, requiring specialist software, Baron and Kenny's (1986) relatively more straightforward approach was used. Our main independent variables Cars and Trees - contain multiple levels, but could be recoded into dichotomous variables, so as to have a single regression coefficient. The rationale justifying this decision and the outcomes are described in the Results pertaining to Hypothesis 6.

\subsubsection{ANOVA}

While MLM analyses were important for statistical testing, ANOVA was used to explore the pattern of the relationship. This is appropriate because the assumptions are not relevant for purposes of producing means plot diagrams.

\subsection{Preliminary analyses}

Histograms were produced for all dependent variables and mediator variables. Most were approximately normally distributed except for the House Price Estimation and Income Estimation. Therefore, these variables were transformed by a logarithm of base ten.

As the House Price Estimation and Income Estimation items were each asked twice per street scene - once for Property A and once for Property B - new variables were created that took the mean value of Property A and Property B, to produce more reliable figures for each street scene.

Given that these variables were also logarithmically transformed for the multi-level model analyses, the variables are referred to in the analysis and results sections as 'LogPriceMean' and 'LogIncomeMean'. However, for the means plots, the non-transformed variables were used, and these variables are simply referred to as House Price Estimation and Income Estimation.

The intraclass correlation (ICC) was calculated by running a null (or intercept-only) model on the important dependent variable LogPriceMean). The ICC was calculated, as described by Hox (2010), by dividing the intercept estimate by the sum of the intercept estimate and the residual estimate: $0.024486 /(0.024486+0.022067)=0.526$.

Thus, the ICC is equal to .53 with LogPriceMean as the dependent variable, meaning that $53 \%$ of the variance in estimated house price can be attributed to differences between subjects. This shows that multi-level analysis is the appropriate method of analysis.

Three questions were asked on how realistic participants perceived the photographs to be, scores ranging from 1 (Strongly Disagree) to 5 (Strongly agree): "I was able to imagine myself in the street scene depicted in the photographs" $(M=3.98, S D=.83)$; "I found the photographs to be realistic" ( $M=3.23, S D=1.16)$; and "I noticed something unusual about the photograph" $(M=3.82, S D=1.30)$.
This suggests that participants generally could imagine themselves in the street scene shown and a high number found them to be realistic. On the other hand, many participants also seemed to notice something unusual about the photos. This seemed to be caused more by the edited cars, as there were approximately 175 comments about the artificial appearance of the cars compared to just 22 comments on the trees.

The variable Architecture was included as a predictor in all of the multilevel model analyses as this variable represented the variance caused by the photograph itself. Therefore, to correct for the effect of the photograph, Architecture is mentioned as a predictor but statistics are not reported as they are not the focus of the hypotheses of this research.

\section{Results}

\subsection{Hypotheses 1, 2: parked cars and street tree density on house evaluation}

A multilevel model (MLM) analysis was run with Architecture, Cars and Trees as factors on the three House Evaluation measures: House Price (LogPriceMean), Property Affect and Income Estimation (LogIncomeMean).

\subsubsection{House price}

The tests of fixed effects on LogPriceMean gave a non-significant result for Cars $F(3,887.20)=1.81, p=.14$ suggesting that Cars had no significant influence on House Price Estimation. Trees received a significant result $F(2,885.83)=5.78, p=.003$, suggesting that street tree density did have an influence on house price estimation. The deviance $^{1},-2$ Restricted Log Likelihood, was -1166.52 .

Results from Table 1 suggest that both $25 \%$ Trees and $50 \%$ Trees are significantly different from $0 \%$ Trees but $25 \%$ Trees is not significantly different from $50 \%$ Trees. Fig. 4 shows the ANOVA means plot of Trees on mean House Price Estimation, which suggests a general positive relationship between Street Tree Density and House Price Estimation. When there were no trees, the price estimated was €192,073; with $25 \%$ tree cover it was $€ 201,771$; and with $50 \%$ tree cover it was $€ 203,740$. This equates to a mean increase in house price estimation of $5.05 \%$ for properties in a street with $25 \%$ tree cover compared to $0 \%$ tree cover, and $6.07 \%$ for $50 \%$ tree cover compared to $0 \%$ tree cover.

In the means plot in Fig. 4, the gap in mean House Price Estimation is much larger between the $0 \%$ and $25 \%$ Trees level than between the $25 \%$ and $50 \%$ Trees level. In the MLM analysis, no significant difference was found between $25 \%$ and $50 \%$ Trees. This suggests that the relationship between Trees and House Price Estimation is not linear but rather curvilinear.

\subsubsection{Property affect}

The tests of fixed effects on Property Affect gave a significant result for Cars $F(3,998.05)=6.31, p<.001$ suggesting that Cars influenced participants' opinion of attractiveness of the properties. Participants liked properties that were in street scenes with an overflowing number of parked cars much less, as shown in Fig. 5. Significant differences were only found between $120 \%$ and each of the other levels (see Table 2). Combined with the graph in Fig. 5, there seems to be evidence for the relationship to be curvilinear rather than linear.

\footnotetext{
${ }^{1}$ The deviance, the -2 Restricted Log Likelihood (-2RLL) is a measure of lack of fit of the model on the data. So, the closer the deviance is to zero, the better the model fits with the data. It is not directly interpretable but it used for comparing different models' fit with a certain data set. The -2RLL values for the Model 1 MLMs were -1166.52 when LogPriceMean was the dependent variable; 2938.32 for Property Affect; and -1264.85 for LogIncomeMean. As the authors did not use the deviance as different models were not compared, the -2RLL values for the other models were not reported. If the reader would like to know these figures, they would be advised to contact the author.
} 
Table 1

Coefficient estimates of fixed effects of Trees on LogPriceMean.

\begin{tabular}{lllll}
\hline $\begin{array}{l}\text { Level of Trees (versus comparison Tree } \\
\text { Level) }\end{array}$ & Estimate & $S E$ & $t$ & $p$ \\
\hline $0 \%$ Trees (versus 50 \% Trees) & & & & \\
\hline $25 \%$ Trees (versus 50 \% Trees) & .0214 & .00864 & -2.48 & .013 \\
$50 \%$ Trees & $\begin{array}{l}\text { Reference } \\
\text { Reference }\end{array}$ & & & .0087 \\
$25 \%$ Trees (versus 0 \% Trees) & .0278 & .00861 & 3.24 & .001 \\
$50 \%$ Trees (versus 0 \% Trees) & .0214 & .00864 & 2.48 & .013 \\
\hline
\end{tabular}

Trees received a non-significant result $F(2,994.40)=.40, p=.67$ suggesting that Street Tree Density did not influence Property Affect.

\subsubsection{Income estimation}

The tests of fixed effects on LogIncomeMean gave a non-significant result for cars $F(3,872.23)=1.62, p=.18$ and a marginally non-significant result for Trees $F(2,871.25)=2.73, p=.066$ suggesting that income estimation was not influenced by either Cars or Trees.

Overall, the results provide a mix of hypotheses confirmed and rejected: Cars affect Property Affect, selectively confirming Hypothesis 1,

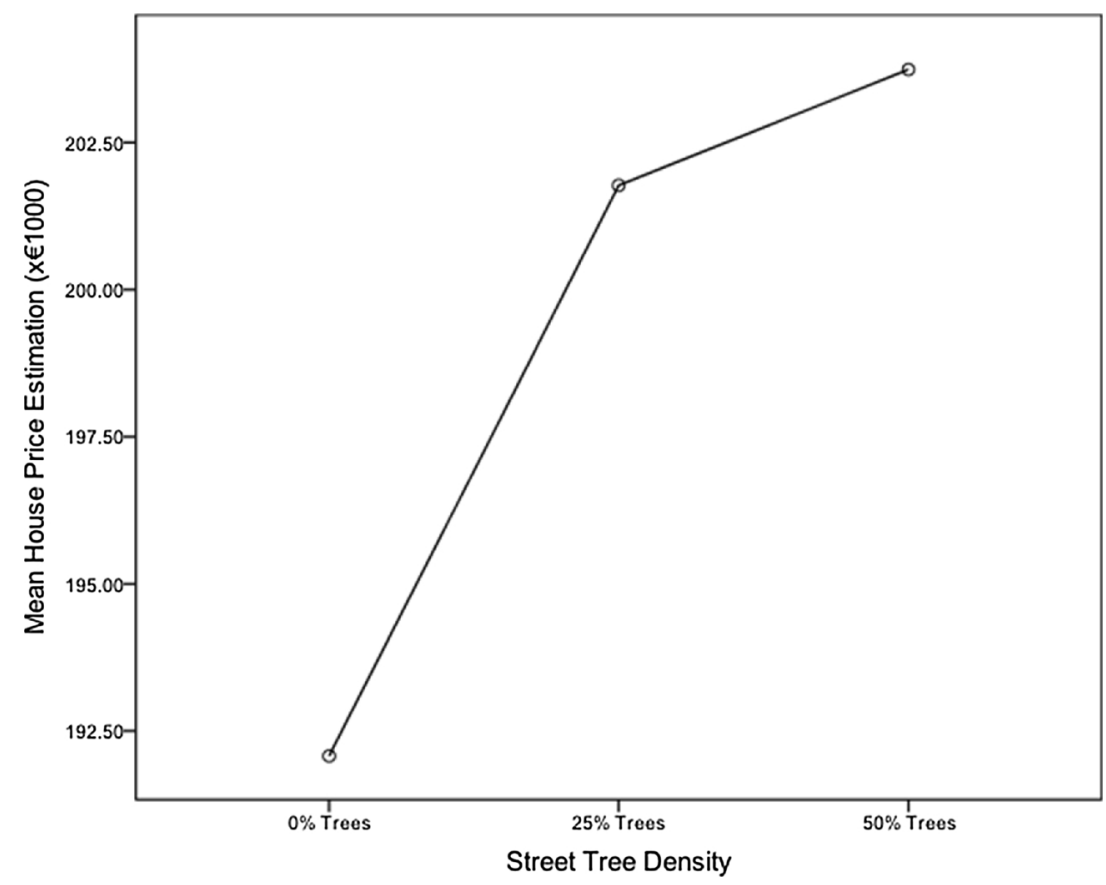

Fig. 4. ANOVA means plot of Street Tree Density on mean House Price Estimation ( $€ 1000 s)$.

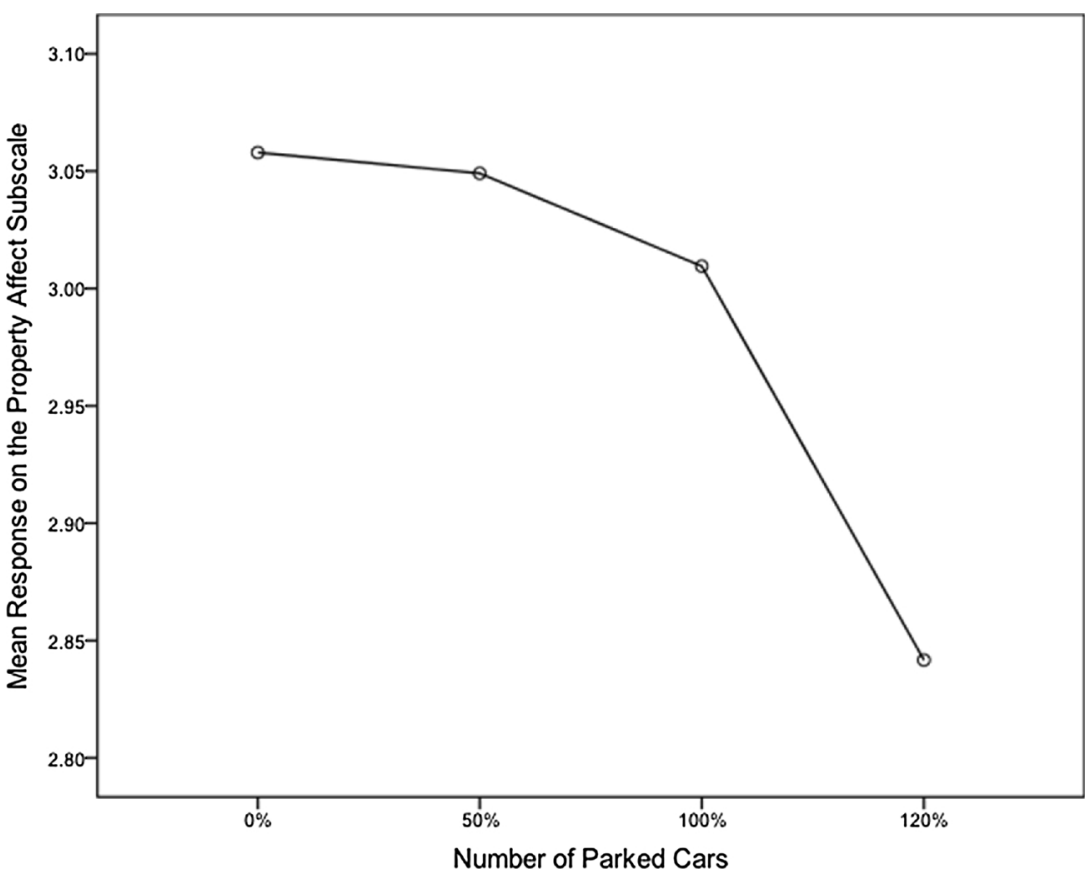

Fig. 5. ANOVA means plot of the Number of Parked Cars on the Property Affect subscale. 
Table 2

Coefficient estimates of fixed effects of Number of Parked Cars on Property Affect.

\begin{tabular}{lllll}
\hline $\begin{array}{l}\text { Level of number of parked cars (versus } \\
\text { comparison car level) }\end{array}$ & Estimate & $S E$ & $t$ & $p$ \\
\hline $0 \%$ Cars (versus $120 \%$ Cars) & .296 & .0714 & 4.15 & $<.001$ \\
$50 \%$ Cars (versus $120 \%$ Cars) & .217 & .0718 & 3.02 & .003 \\
$100 \%$ Cars (versus 120 \% Cars) & .211 & .0707 & 2.98 & .003 \\
$120 \%$ Cars & Reference & & & \\
$0 \%$ Cars (versus $50 \%$ Cars) & .079 & .0713 & 1.11 & .267 \\
$50 \%$ Cars & Reference & & & \\
$100 \%$ Cars (versus $50 \%$ Cars) & -.006 & .0714 & -.085 & .932 \\
$120 \%$ Cars (versus 50 \% Cars) & -.217 & .0718 & -3.017 & .003 \\
$0 \%$ Cars (versus $100 \%$ Cars) & .085 & .0716 & 1.19 & .234 \\
$50 \%$ Cars (versus 100 \% Cars) & .006 & .0714 & .085 & .932 \\
$100 \%$ Cars & Reference & & & \\
$120 \%$ Cars (versus 100 \% Cars) & -.211 & .0707 & -2.978 & .003 \\
\hline
\end{tabular}

Trees affect House Price, selectively confirming Hypothesis 2. For Income Estimation both hypotheses are rejected.

3.1.4. Hypothesis 3: neighborhood appraisal is positively related to house evaluation

Figs. 6-8 show ANOVA means plots of the Neighborhood Appraisal subscale on mean House Price Estimation, Property Affect and mean Income Estimation respectively. These suggest that higher scores on the Neighborhood Appraisal subscale led to increased House Evaluation on all three measures. A multi-level analysis was performed with Neighborhood Appraisal on the three House Evaluation measures with Cars, Trees, and Architecture included as predictors for correction. Neighborhood Appraisal received a significant result for all three House Evaluation measures: LogPriceMean, $F(12,878.36)=5.32, p<.001$; Property Affect, $F(12,990.36)=45.66, p<.001$; and LogIncomeMean, $F(12,862.09)=4.97, p<.001$. These results strongly confirm Hypothesis 3.

3.1.5. Hypotheses 4 and 5: effects of cars and trees on neighborhood appraisal

A multi-level model analysis was run with Cars and Trees on
Neighborhood Appraisal controlling for Architecture. Overall, Hypotheses 4 and 5 are confirmed: both Cars, $F(3,1056.88)=13.06$, $p<.001$, and Trees, $F(2,1052.91)=6.38, p=.002$, received highly significant results. Figs. 9 and 10 show ANOVA means plots that give an indication of the pattern of the relationships.

Fig. 9 shows the pattern between Cars and Neighborhood Appraisal. It seems as though the number of cars did not affect Neighborhood Appraisal until there was an overflowing number of parked cars. Table 3 shows the coefficient estimates for the different levels of Cars. The $t$ tests from Table 3 support what can be seen from Fig. 9, that only the $120 \%$ level of parked cars had an influence on Neighborhood Appraisal.

The pattern in Fig. 10 suggests that there was a larger difference between $0 \%$ and $25 \%$ trees and a small difference between $25 \%$ and $50 \%$ trees on Neighborhood Appraisal, suggesting a non-linear relationship, comparable with the relationship between Trees and House Price Estimation, as depicted in Fig. 4. Table 4 shows the results from the coefficient estimates for each level of trees, first with $50 \%$ as the reference level, then with $0 \%$ as the reference level, showing that $0 \%$ trees resulted in a significantly lower Neighborhood Appraisal whereas there was no significant difference between $25 \%$ and $50 \%$ Trees.

3.1.6. Hypothesis 6. Neighborhood appraisal mediates effects of cars and trees on house evaluation

Cars and Trees relate to different aspects of House Evaluation: Cars only relate to Property Affect, Trees relate only to House Price Estimation. Both Cars and Trees relate to Neighborhood Appraisal which relates to all aspects of House Evaluation. Given these findings Hypothesis 6 was split up according to the two dependent variables.

3.1.7. Hypothesis 6a: the effect of cars on property affect is mediated by neighborhood appraisal

Cars was recoded such that $100 \%$ or lower was recoded as one level, and $120 \%$ as the other level, as the $120 \%$ level differed from the three others that did not significantly differ from each other (see Table 2 and 3). Thus 'CarsBinary' was created. Consequently, the total effect of CarsBinary on Property Affect is, $c=.241, F(1$, 994.21) $=17.11, p<.001$, with Trees and Architecture included as factors for correction, but without Neighborhood Appraisal so as to

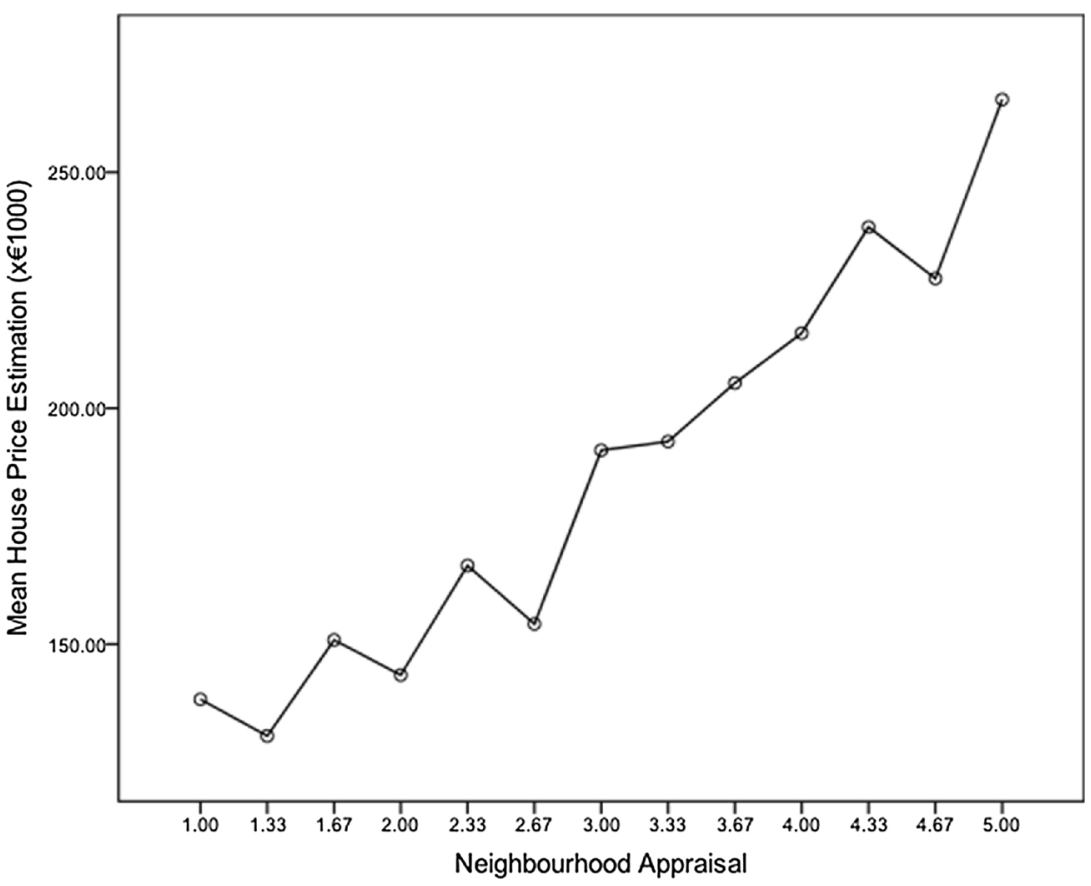

Fig. 6. ANOVA means plot of Neighborhood Appraisal on House Price. 


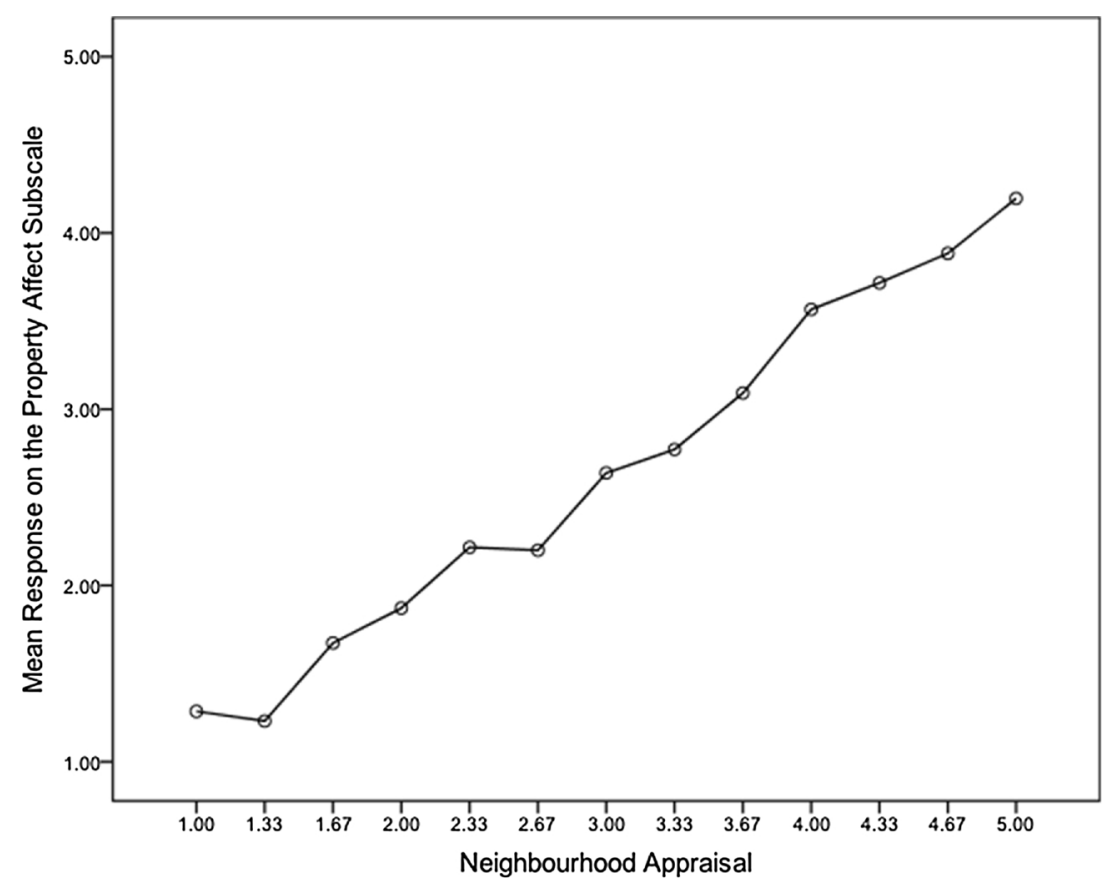

Fig. 7. ANOVA means plot of Neighborhood Appraisal on the Property Affect subscale.

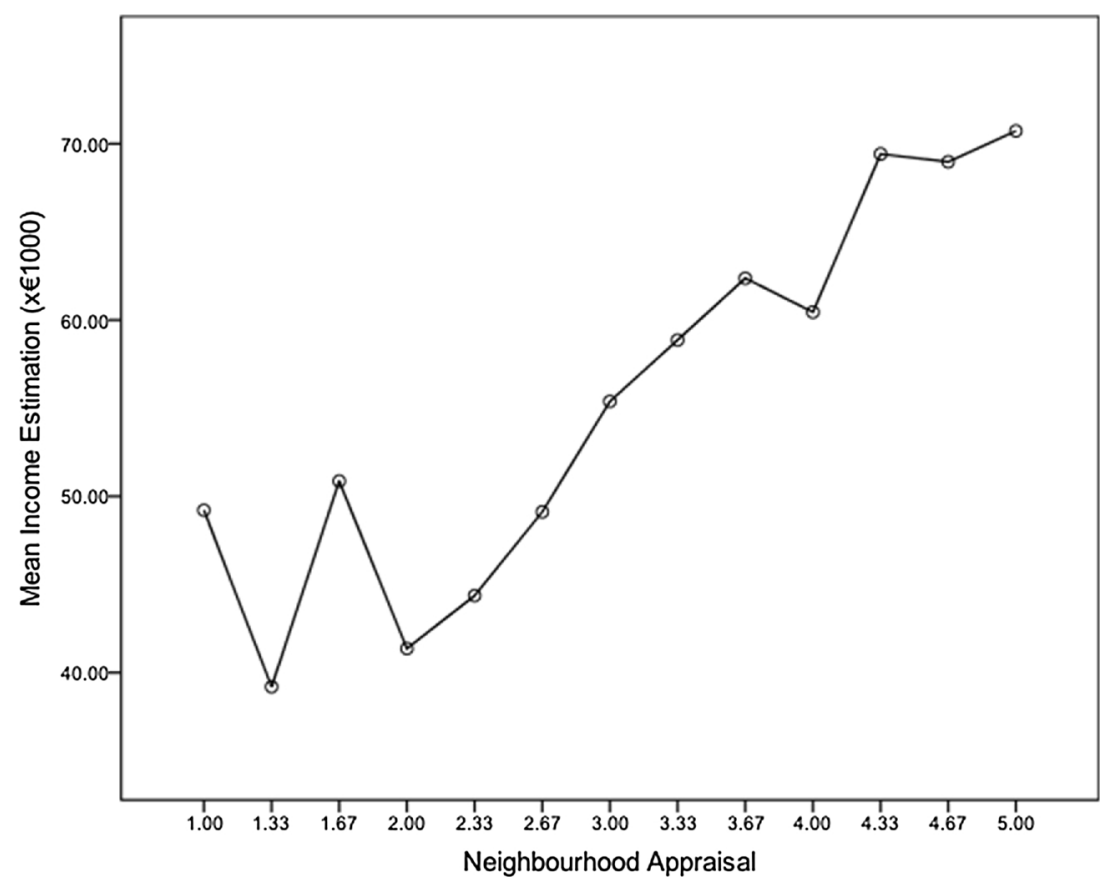

Fig. 8. ANOVA means plot of Neighborhood Appraisal on mean Income Estimation.

calculate the total effect. CarsBinary on Neighborhood Appraisal was found to be highly significant, $a=.313, F(1,1051.99)=38.66, p<$ .001. An MLM analysis was performed on Property Affect by Neighborhood Appraisal and CarsBinary, which was found to be non-significant for CarsBinary, (direct effect) $c^{\prime}=.019, F(1,986.80)=.16$, $p=.689$; and highly significant for Neighborhood Appraisal, $F(12$, $991.85)=45.82, p<.001$. These outcomes demonstrate a complete mediation effect by Neighborhood Appraisal between Cars and Property Affect, when comparing a street with an overflowing number of parked cars, versus a street with a legal number of parked cars, confirming Hypothesis 6a.
3.1.8. Hypothesis $6 b$ : is the effect of trees on house price estimation mediated by neighborhood appraisal?

To perform the analysis, the variable Trees was recoded into a dichotomous variable such that $25 \%$ and $50 \%$ Trees became one level and $0 \%$ Trees remained as the other level, in accordance with the significant effects found between $0 \%$ and $25 \%$ Trees but not between $25 \%$ and $50 \%$ Trees (see Table 1 and 4). This recoded variable was named 'TreeBinary'. Consequently, an MLM analysis was done with TreeBinary on LogPriceMean, with Cars and Architecture included as factors for correction, but without Neighborhood Appraisal so as to calculate the total effect, $c=-.0247, F(1,882.61)=11.03, p=.001$. TreeBinary on Neighborhood Appraisal was found to be highly 


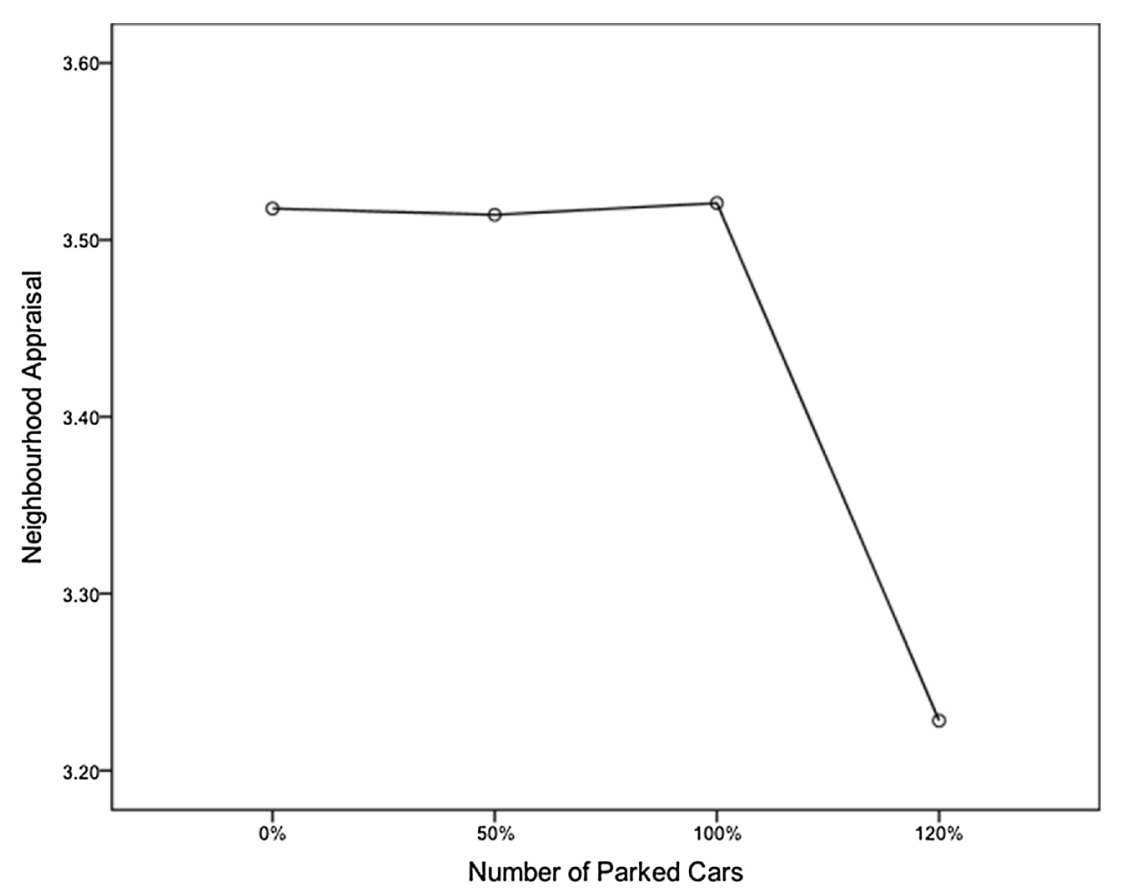

Fig. 9. ANOVA means plot of Cars on the Neighborhood Appraisal subscale.

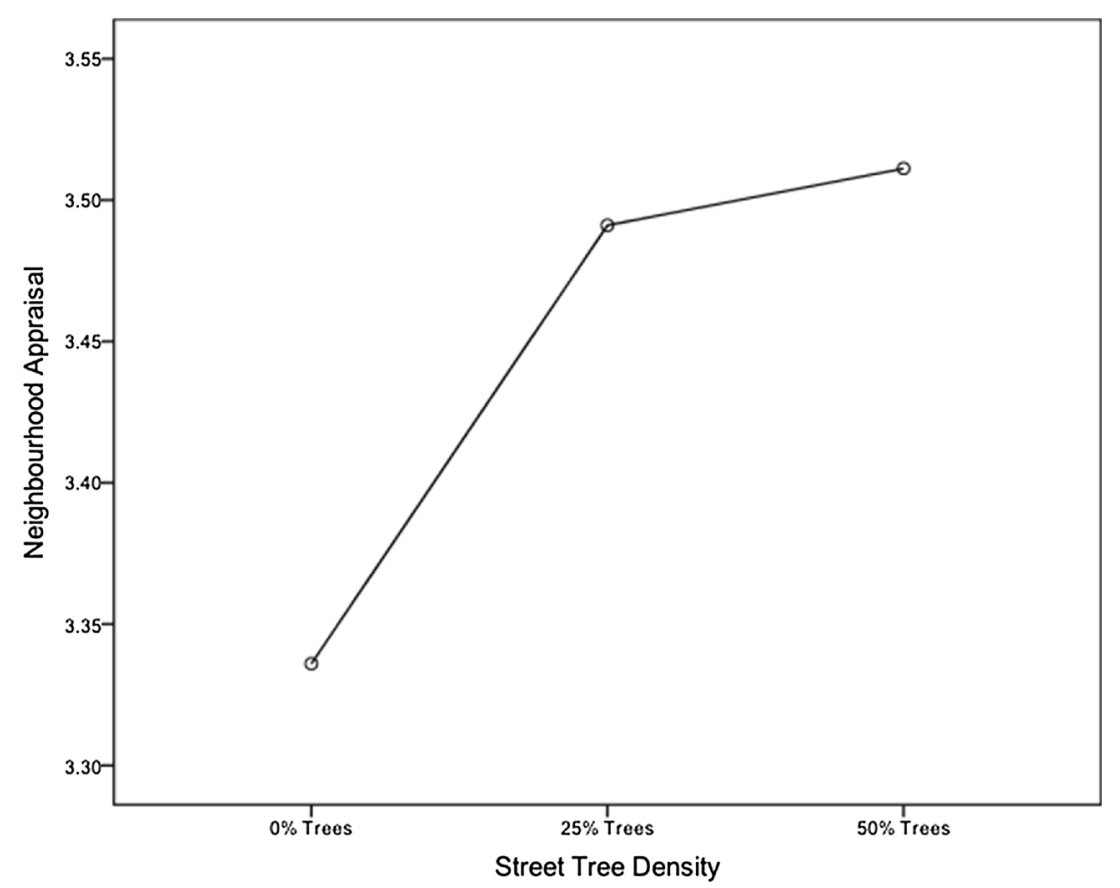

Fig. 10. ANOVA means plot of Street Tree Density on the Neighborhood Appraisal subscale.

significant, $a=-.164, F(1,1041.99)=12.74, p<.001$. An MLM analysis was performed on LogPriceMean by Neighborhood Appraisal and TreeBinary, which was found to be significant for TreeBinary, (direct effect) $c^{\prime}=-.0180, F(1,870.28)=6.06, p=.014$; and highly significant for Neighborhood Appraisal, $F(12,879.18)=5.34, p<$ .001 . Because $c$ ' was found to be smaller than $c$, but was non-zero, there is evidence consistent with a partial mediation effect of Neighborhood Appraisal between Trees on House Estimation, confirming Hypothesis $6 b$.

\section{Discussion}

The aim of this study was to investigate how number of parked cars and tree density in a residential street affect people's appraisal of a neighborhood, and how these attributes of the street and neighborhood affect the appraisal of a property and the monetary value they associate with that property. Experimental manipulation of these two factors cars and trees - combined has not been reported before in the literature.

Results show that both cars and trees affect Neighborhood Appraisal and House Evaluation. Parked cars affect Neighborhood Appraisal and the affective measure of House Evaluation, Property Affect. Trees affect Neighborhood Appraisal and the estimated house price. Neighborhood 
Table 3

Coefficient estimates of fixed effects of Number of Parked Cars on Neighborhood Appraisal.

\begin{tabular}{|c|c|c|c|c|}
\hline $\begin{array}{l}\text { Level of number of parked cars (versus } \\
\text { comparison car level) }\end{array}$ & Estimate & $S E$ & $t$ & $p$ \\
\hline $0 \%$ Cars (versus $120 \%$ Cars) & .331 & .0617 & 5.36 & $<.001$ \\
\hline $50 \%$ Cars (versus $120 \%$ Cars) & .287 & .0620 & 4.64 & $<.001$ \\
\hline $100 \%$ Cars (versus $120 \%$ Cars) & .319 & .0613 & 5.201 & $<.001$ \\
\hline $120 \%$ Cars & Reference & & & \\
\hline $0 \%$ Cars (versus $50 \%$ Cars) & .0434 & .0616 & .704 & .481 \\
\hline $50 \%$ Cars & Reference & & & \\
\hline $100 \%$ Cars (versus $50 \%$ Cars) & .0314 & .0617 & .509 & .611 \\
\hline $120 \%$ Cars (versus $50 \%$ Cars) & -.287 & .0620 & -4.640 & $<.001$ \\
\hline
\end{tabular}

Table 4

Coefficient estimates of fixed effects of Street Tree Density on Neighborhood Appraisal.

\begin{tabular}{lllll}
\hline Level of Trees & Estimate & $S E$ & $t$ & $p$ \\
\hline $0 \%$ Trees (versus 50 \% Trees) & -.169 & .0532 & -3.17 & .002 \\
$25 \%$ Trees (versus 50 \% Trees) & -.010 & .0537 & -.182 & .856 \\
$50 \%$ Trees & $\begin{array}{l}\text { Reference } \\
\text { \% Trees }\end{array}$ & & & \\
$25 \%$ Trees (versus 0 \% Trees) & .159 & .0531 & 2.993 & .003 \\
$50 \%$ Trees (versus 0 \% Trees) & .169 & .0532 & 3.169 & .002 \\
\hline
\end{tabular}

Appraisal affects all three measures of House Evaluation - estimated house price, estimated income and Property Affect - and mediates the relation of cars and Property Affect, and the relation of trees and estimated house price. The two environmental features manipulated in this experiment apparently work on different components of the experience of quality. Their effects also show specific patterns.

The number of parked cars only influenced Property Affect once the number of cars reached $120 \%$. Why overflowing parked cars reduced Property Affect is explained by the complete mediation by Neighborhood Appraisal. Participants may have felt that the overflowing number of cars meant that the street was overcrowded and that residents were behaving in anti-social manners, reducing Neighborhood Appraisal, which in turn led to reduced Property Affect. Interestingly, participants did not estimate lower prices for those properties with 120 $\%$ cars, despite rating them significantly lower in terms of Property Affect and Neighborhood Appraisal. This outcome remains to be an intriguing one, and provides opportunities for further research.

Trees in the street increased participants' house price estimation by around $5 \%$ for $25 \%$ tree cover and $6 \%$ for $50 \%$ tree cover. These two tree density levels did not significantly differ for Neighborhood Appraisal, leading us to dichotomize the tree density variable for the mediation analyses, with no trees as one level and 25 or $50 \%$ tree density as the other level. Mediation by Neighborhood Appraisal proved to be partial, showing that presence or absence of trees affected house price estimation, partly through its effect on Neighborhood Appraisal. These results can be compared with previous findings, such as that of Stamps (1997), who found that trees had a moderate, positive effect on preferences for streetscapes. Our participants did not rate properties as significantly more attractive on the Property Affect subscale when there were trees in the street, despite their willingness to pay more for them. This finding leads to intriguing research questions on the economic decisions made by the participants.

To investigate why trees influenced house price estimation without influencing Property Affect, and why the opposite occurred for cars, perhaps one should investigate the items of the two House Evaluation measures more closely. The house price estimation item asks for the monetary value of the property in terms of what the participants think the market price would be: "What do you think the price of this property is?". Therefore, the question, thus phrased, is more related to the society, and factors such as demand and supply. The Property Affect items are more related to the personal opinion of the respondent, for example: "I find this property attractive", and so less related to others in society. Given the results, it could be conceived that trees increased house price estimations because participants acknowledge that trees are widely held desirable and so would lead to higher prices. On the other hand, parked cars resulted in reduced Property Affect, but not in reduced price estimates, because the participants themselves apparently had lower appreciation for houses in this crowded setting. The explanation for these somewhat contrasting findings is, again, hard to give on the basis of our data. The results from this study require further research but potentially reveal a difference between what people want personally from a residential property and what people believe is wanted by others.

\subsection{Limitations and options for future research}

Each of the four original photograph showed houses of a different architectural style so as to increase the generalizability of the results. This quality of the photographs was referred to as the variable 'Architecture'. This variable was included as a predictor in the MLM analyses so as to correct for the effect of the photograph used; but it was neither the aim of this research, nor scientifically sound to test the effects of architecture as an independent variable. Each of the four photographs used for the 12 permutations ultimately varied in a number of ways other than architectural style, such as weather, lighting, and angle of photograph. All these were constants in the comparisons on which the outcomes of the study are based but did not refer to architectural style alone. If the effect of architectural style, similar to Stamps (1999) who researched building facades, is to be researched, we recommend using images that keep aspects of the street scene other than the architectural style, such as weather, lighting, road layout, as constant as possible.

Although many participants left comments on the fact that they noticed that the cars were artificially added to the photographs, the mean response for the question on being able to imagine oneself in the street scene was relatively high, suggesting that the photographs were realistic enough for the purposes of the experiment. Furthermore, given that the effect of trees on house price estimation are very much in line with previous results, (e.g., Pandit et al., 2013), it seems unlikely that the artificiality of the photographs led to reduced validity.

Most of the participants in this study were students of Leiden University, and therefore not a random sample of the population of home buyers in the Netherlands. The results found in this study may not completely reflect price estimates among current homebuyers but represent the estimates of a generation that is soon to become home buyers. But we also emphasized that it is not so much price estimates as it is the differences in price estimates as a function of our experimental manipulations that we are interested in. The mean increase of $5 \%$ in house price estimation as a result of trees being added to the street in this study is in line with previous studies that have used hedonic modelling (i.e. real house purchasing data), such as Pandit et al. (2013), who found an approximate increase of $4.27 \%$ in house price. Given that this study's results are close to that of a study based on revealed preferences external validity seems strong, at least in comparisons with studies that were also performed in western cultures.

As the presence of parked cars did not affect estimations of house price, it would be interesting to see how car ownership affects this relationship. No literature could be found that investigates exactly how car ownership interacts with the number of parked cars in the street (assuming no availability of off-street parking) on house price estimations. A follow-up of this study could repeat this experiment while including questions on car usage behavior and car ownership. Such a follow-up study might also look at the judgements home buyers make about the neighborhood based on the type of cars parked on the road. Bayley et al. (2004) found that individuals often evaluate a car by imagining what type of person the owner might be. So, looking at the 
parked cars in a street may give an impression to a potential homebuyer as to what kind of people live on that street. This could lead to an appraisal of the neighborhood and influence the prospective homebuyer's decision. This study focused on the number of parked cars in the street, controlling for the style of cars to keep them uniform, so as to reduce unexplained error in the analysis. Manipulating the kind of cars - their type and economic value - might be an interesting follow-up study to further investigate Neighborhood Appraisal and House Evaluation.

\subsection{Implications, financial and otherwise}

Manipulating numbers of cars and trees in different housing situations has led to findings that are interesting, partly unexpected, and clearly relevant. Both cars and trees affect the evaluation of the neighborhood but these effects mediate the evaluation of houses in different ways. Many cars in the street lower the affective evaluation of a house in such a street but not its estimated price. Presence of trees, on the other hand, does not impact the affective evaluations of houses but does change house price estimates. Having even a modest number of trees in the street was found to increase house price estimation by $5 \%$, which is exactly as expected given Anderson and Cordell's (1988) conclusion from a review of several studies that "An estimate of $5 \%$ as the average value that trees may add to a single-family residence is in line with research using both direct and statistical strategies for controlling comparability" (p. 163). In this experiment, having $25 \%$ tree cover increased the estimated value of each house by a mean of $€ 9698$. This is comparable to the findings by Donovan and Butry (2010) that street trees added on average "\$8870 to the price of a house, which represents $3.0 \%$ of median sales price" (p. 81). Assuming there is just one tree for every three properties, each tree could add just under $€ 30,000$ of real estate value, according to the results of our experiment. Given all the other benefits mentioned earlier, homeowners clearly have plenty to gain from ensuring there are trees in their street. But finances may not be the ultimate criterion, or at least not the only one. A warm feeling for one's house also depends on neighborhood qualities that suggest pleasant and unthreatening social interaction.

\subsection{Conclusions}

This study investigated the relevance of the presence of cars and trees in the street in determining the quality of the residential environment. Starting from the idea that having strong, i.e., quantitative, fairly objective, variables to assess the quality of an environment help to defend its quality in policy making processes, we chose a financial measure - estimated house price - in combination with affective measures of house and neighborhood as dependent variables. As the first study that looked at both environmental factors in combination we investigated whether their effects might compensate for each other, both on the level of neighborhood and that of the residence itself. We reasoned that presence of cars might detract from residential quality and that presence of trees might increase residential quality. We wondered whether and to what extent one might compensate for the other. In a laboratory experiment 4 original photographs, street scenes from different architectural styles, were systematically filled with cars and trees in a 4 (presence of cars parked in the street) by 3 (density of street trees) full factorial design to create 48 different photographs. These were rated on qualities of the neighborhood and quality of residences.

Results showed that both cars and trees had an effect on the appraisal of the neighborhood, negative for cars, positive for trees, but that effects on appraisal of the residences was dependent on the kind of dependent variable. These effects were qualified: Cars had an effect on the affective appraisal of the residence, but only when apparent norm violation was perceived; trees influenced the estimated house price, but similarly for both levels of density. The size of the 'tree' effect closely corresponds with earlier research. Both effects were mediated by neighborhood appraisal.

Results clearly suggest further research, to expand on the current findings and overcome some of its limitations. First of all the interesting differentiation between effects of cars and of trees on financial and affective measures could be subject of further research. Secondly, other populations would be interesting to study, in particular car owners. And thirdly how the type and price of cars displayed might affect attributions of the kind of people apparently living in the streets and consecutively the attractiveness and price estimates of a home in that street.

\section{Declaration of Competing Interest}

The authors declare that there is no conflict of interest regarding the submission and possible publication of this manuscript.

\section{Acknowledgements}

We thank dr. Elise Dusseldorp, Methodology and Statistics Unit, department of Psychology, Leiden University, for her advice on the analysis of the data, specifically the Multi-Level Modelling, and dr. Emma ter Mors, Social, Economic, and Organizational Psychology Unit, department of Psychology, Leiden University, for her constructive comments on an earlier version of this paper. We also thank anonymous reviewers for their very useful comments that substantially improved the paper.

Funding of this study, for payment of participants, was provided by the Department of Social, Economic, and Organizational Psychology of Leiden University.

\section{References}

Anderson, L., Cordell, H., 1988. Influence of trees on residential property values in Athens, Georgia (U.S.A.): a survey based on actual sales prices. Landsc. Urban Plan. 15, 153-164. https://doi.org/10.1016/0169-2046(88)90023-0.

Baron, R.M., Kenny, D.A., 1986. The moderator-mediator variable distinction in social psychological research: conceptual, strategic, and statistical considerations. J. Pers. Soc. Psychol. 51, 1173.

Bayley, M., Curtis, B., Lupton, K., Wright, C., 2004. Vehicle aesthetics and their impact on the pedestrian environment. Transp. Res. D Transp. Environ. 9, 437-450. https://doi. org/10.1016/j.trd.2004.08.002.

Bonaiuto, M., Alves, S., 2012. Residential Places and Neighborhoods: Toward Healthy Life, Social Integration, and Reputable Residence. Oxford Handbooks Online, pp. 221-247. https://doi.org/10.1093/oxfordhb/9780199733026.013.0013.

Donovan, G.H., Butry, D.T., 2010. Trees in the city: valuing street trees in Portland, Oregon. Landsc. Urban Plan. 94, 77-83. https://doi.org/10.1016/j.landurbplan. 2009.07.019.

Grinde, B., Patil, G.G., 2009. Biophilia: does visual contact with nature impact on health and well-being? Int. J. Environ. Res. Public Health 6, 2332-2343. https://doi.org/10. 3390/ijerph6092332.

Guo, H., 2013. Residential street parking and car ownership: a study of households with off-street parking in the New York City region. J. Am. Plan. Assoc. 79, 32-48.

Hareli, S., David, S., Lev-Yadun, S., Katzir, G., 2016. Money in your palm: sharp shaped vegetation in the surroundings increase the subjective value of houses. J. Environ. Psychol. 46, 176-187.

Hartig, T., Kahn, P.H., 2016. Living in cities, naturally. May 19. Science 352 (6288), 938-940. https://doi.org/10.1126/science.aaf3759.

Hox, J.J., 2010. Multilevel Analysis: Techniques and Applications. Routledge, New York.

Hunter, A., Baumer, T.L., 1982. Street traffic, social integration, and fear of crime. Sociol. Inq. 52, 122-131.

Hur, M., Nasar, J.L., Chun, B., 2010. Neighborhood satisfaction, physical and perceived naturalness and openness. J. Environ. Psychol. 30, 52-59. https://doi.org/10.1016/j. jenvp.2009.05.005.

Isaacs, R., 2000. The urban picturesque: an aesthetic experience of urban pedestrian places. J. Urban Des. 5, 145-180. https://doi.org/10.1080/713683961.

Jacobs, J., 1961. The Death and Life of Great American Cities. Vintage, New York.

Jacobsen, P., Anderson, C.L., Winn, D.G., Moffat, J., Agran, P.F., Sarkar, S.H., 2000. Child pedestrian injuries on residential streets: implications for traffic engineering. ITE J. 70, 71-75.

Jurkovič, N.B., 2014. Perception, experience and the use of public urban spaces by residents of urban neighborhoods. Urbani Izziv 25, 107-125. https://doi.org/10.5379/ urbani-izziv-en-2014-25-01-003

Kiran, G.S., Kinnary, S., 2011. Carbon sequestration by urban trees on roadsides of Vadodara city. Int. J. Eng. Sci. Technol. 3, 3066-3070.

Luttik, J., 2000. The value of trees, water and open space as reflected by house prices in the Netherlands. Landsc. Urban Plan. 48, 161-167. https://doi.org/10.1016/s0169- 
2046(00)00039-6.

Maco, S.E., McPherson, E.G., 2002. Assessing canopy cover over streets and sidewalks in street tree populations. J. Arboricult. 28, 270-276. Retrieved from. http://www. treesearch.fs.fed.us/pubs/48726.

Maher, B.A., Ahmed, I.A., Davison, B., Karloukovski, V., Clarke, R., 2013. Impact of roadside tree lines on indoor concentrations of traffic-derived particulate matter. Environ. Sci. Technol. 47, 13737-13744. https://doi.org/10.1021/es404363m.

McPherson, E.G., 1994. Energy-saving Potential of Trees in Chicago. Chicago's Urban Forest Ecosystem: Results of the Chicago Urban Forest Climate Project. Gen. Tech. Rep. NE-186. Radnor [Newtown Square]. PA: US Department of Agriculture, Forest Service, Northeastern Research Station, pp. 95-113.

Morales, D., Boyce, B.N., Favretti, R.J., 1976. The contribution of trees to residential property value: Manchester, Connecticut. Valuation 23, 27-43.

Mullan, E., 2003. Do you think that your local area is a good place for young people to grow up? The effects of traffic and car parking on young people's views. Health Place 9, 351-360. https://doi.org/10.1016/s1353-8292(02)00069-2.

Mullaney, J., Lucke, T., Trueman, S.J., 2015. A review of benefits and challenges in growing street trees in paved urban environments. Landsc. Urban Plan. 134 157-166.

Oke, T.R., Crowther, J.M., McNaughton, K.G., Monteith, J.L., Gardiner, B., 1989. The micrometeorology of the urban forest [and discussion]. Philosop. Trans. R. Soc. B: Biol. Sci. 324 (1223), 335-349. https://doi.org/10.1098/rstb.1989.0051.

Orland, B., Vining, J., Ebreo, A., 1992. The effect of street trees on perceived values of residential property. Environ. Behav. 24, 298-325. https://doi.org/10.1177/ 0013916592243002.

Pandit, R., Polyakov, M., Sadler, R., 2014. Valuing public and private urban tree canopy cover. Aust. J. Agric. Resour. Econ. 58, 453-470. https://doi.org/10.1111/14678489.12037.

Pandit, R., Polyakov, M., Tapsuwan, S., Moran, T., 2013. The effect of street trees on property value in Perth, Western Australia. Landsc. Urban Plan. 110, 134-142. https://doi.org/10.1016/j.landurbplan.2012.11.001.

Payne, B.R., 1973. The twenty-nine tree home improvement plan. Nat. Hist. 82, 74-75

Payne, B.R., Strom, S., 1975. The contribution of trees to the appraised value of unimproved residential land. Valuation 22, 36-45.
Qualtrics (2019). Retrieved August 26, 2019 from https://www.staff.universiteitleiden. $\mathrm{nl} / \mathrm{ict} / \mathrm{it}$-and-research/survey-tools/qualtrics/leiden-university?cf $=$ social-andbehavioural-sciences.

Roy, S., Byrne, J., Pickering, C., 2012. A systematic quantitative review of urban tree benefits, costs, and assessment methods across cities in different climatic zones. Urban For. Urban Green. 11, 351-363.

Saphores, J.D., Li, W., 2012. Estimating the value of urban green areas: a hedonic pricing analysis of the single family housing market in Los Angeles, CA. Landsc. Urban Plan. 104, 373-387.

Shimizu, C., 2014. Estimation of hedonic single-family house price function considering neighborhood effect variables. Sustainability 6, 2946-2960. https://doi.org/10. 3390/su6052946.

Shoup, D.C., 1994. Cashing in on curb parking. Access 4, 20-26.

Smardon, R.C., 1988. Perception and aesthetics of the urban environment: review of the role of vegetation. Landsc. Urban Plan. 15, 85-106. https://doi.org/10.1016/01692046(88)90018-7.

Staats, H., Jahncke, H., Herzog, T.R., Hartig, T., 2016. Urban options for psychological restoration: common strategies in everyday situations. PLoS One 11, e0146213. https://doi.org/10.1371/journal.pone.0146213.

Stamps, A.E., 1997. Some streets of San Francisco: preference effects of trees, cars, wires, and buildings. Environ. Plann. B Plann. Des. 24, 81-93.

Stamps, A.E., 1999. Physical determinants of preferences for residential facades. Environ. Behav. 31, 723-751.

Taylor, M.S., Wheeler, B.W., White, M.P., Economou, T., Osborne, N.J., 2015. Research note: urban street tree density and antidepressant prescription rates-A cross-sectional study in London, UK. Landsc. Urban Plan. 136, 174-179. https://doi.org/10. 1016/j.landurbplan.2014.12.005.

Ulrich, R.S., Simons, R.F., Losito, B.D., Fiorito, E., Miles, M.A., Zelson, M., 1991. Stress recovery during exposure to natural and urban environments. J. Environ. Psychol. 11 201-230. https://doi.org/10.1016/s0272-4944(05)80184-7.

Van den Berg, A.E., Hartig, T., Staats, H., 2007. Preference for nature in urbanized societies: stress, restoration, and the pursuit of sustainability. J. Soc. Issues 63, 79-96. https://doi.org/10.1111/j.1540-4560.2007.00497.x.

Wilson, E.O., 1984. Biophilia. Harvard University Press, Cambridge. 